\title{
Direct endoscopic ultrasound-guided gastroenterostomy using a feeding-tube waterjet system: a teaching video to facilitate understanding of the technique
}

To facilitate the safe and simple introduction of an endoscopic ultrasound (EUS)guided gastroenterostomy technique, we present a step-by-step teaching video of a variant technique for direct EUSguided gastroenterostomy using a feeding tube ( $\bullet$ Video 1$)$. The stages involved are as follows.

1. Preparation: orotracheal intubation, positioning the patient in the left lateral position (maintain water at the Treitz angle), and use of a spasmolytic are recommended.

2. A therapeutic gastroscope is used to pass a 0.035 -inch guidewire and endoscopic retrograde cholangiopancreatography catheter across the stricture until just distal to the Treitz angle.

3. Oroenteric catheter insertion: a radiopaque through-the-scope feeding tube (NJ-8; Cook Medical) is advanced over the guidewire, through the stenosis, and is positioned at the proximal jejunum using fluoroscopic guidance.

4. The gastroscope is carefully removed, maintaining the position of the feeding tube. The guidewire is removed once the scope is out.

5. Enteral loop distension: the feeding tube is connected to a waterjet system (saline and contrast) for continuous infusion into the jejunum until stent deployment.

6. An echoendoscope is advanced following the mesenteric vein (to the mid-stomach body), turning clockwise to identify the Treitz area with the first jejunal loop containing the feeding tube, which is visualized by EUS and fluoroscopy ( $\mathbf{F i g} . \mathbf{1}$ ).

7. Enteral access (the crucial point): the duodenal-jejunal loop (fixed at the Treitz angle) must be positioned in a longitudinal plane and in line with the working channel tract ( $\triangleright$ Fig. 2 ).

8. Stent deployment: the direct "freehand" method using an electrocau-
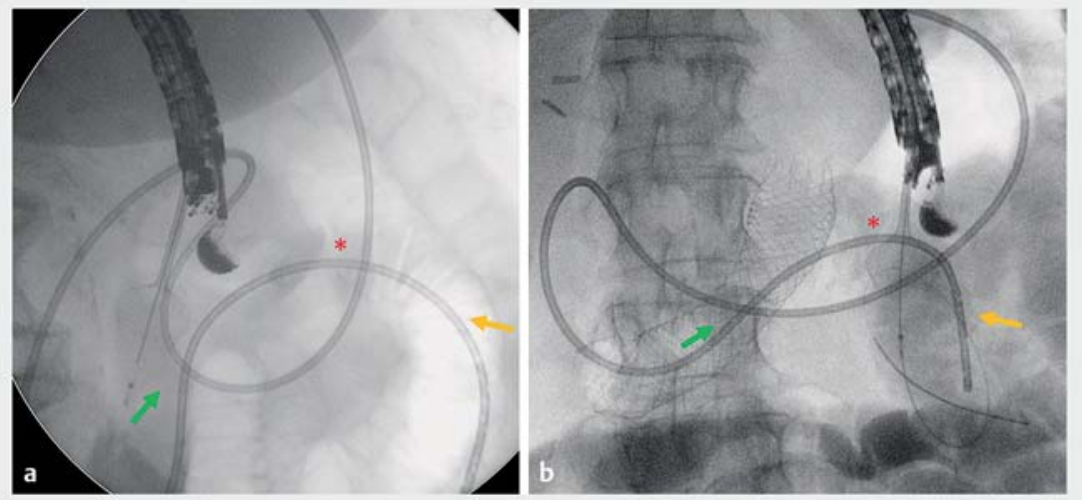

Fig. 1 Fluoroscopic images showing a radiopaque 8-Fr feeding tube (NJ-8, Cook Medical) being advanced across the duodenal stenosis into the proximal jejunum under endoscopic and fluoroscopic guidance. At the Treitz angle or duodenal-jejunal loop (red asterisk), two enteral access options are possible: $\mathbf{a}$ to the duodenal portion (green arrows); $\mathbf{b}$ in the direction of the jejunal loop (yellow arrows).
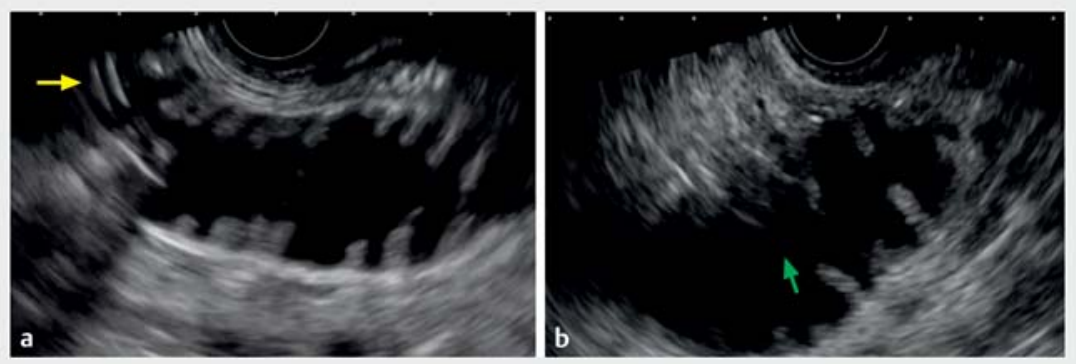

- Fig. 2 Endoscopic ultrasound images showing: a a longitudinal but overly perpendicular plane of a distended enteral loop with the feeding tube within it (yellow arrow), which carries a higher risk of lumen-apposing metal stent (LAMS) misdeployment; $\mathbf{b}$ a longitudinal and oblique plane of the enteral loop at the Treitz angle, and in line with the working channel, which is the ideal plane to avoid pushing away the enteral loop and damaging the contralateral wall. Note: distension of the enteral lumen should be maintained with continuous water infusion until the first flange of the LAMS is released.

tery-enhanced lumen-apposing metal stent (LAMS; HotAxios; $20 \times 10 \mathrm{~mm}$ ) and high settings (pure cut; $160 \mathrm{~W}$ ) is used. After the release of the distal stent flange, a guidewire is advanced. The LAMS is then completely deployed as described.

9. Intra-LAMS dilation up to $12-15 \mathrm{~mm}$. Spontaneous water drainage, and visualization of the enteral lumen (and usually, the feeding tube) to confirm the successful gastroenterostomy ( $\triangleright$ Fig.3).

Endoscopy_UCTN_Code_TTT_1AS_2AG 

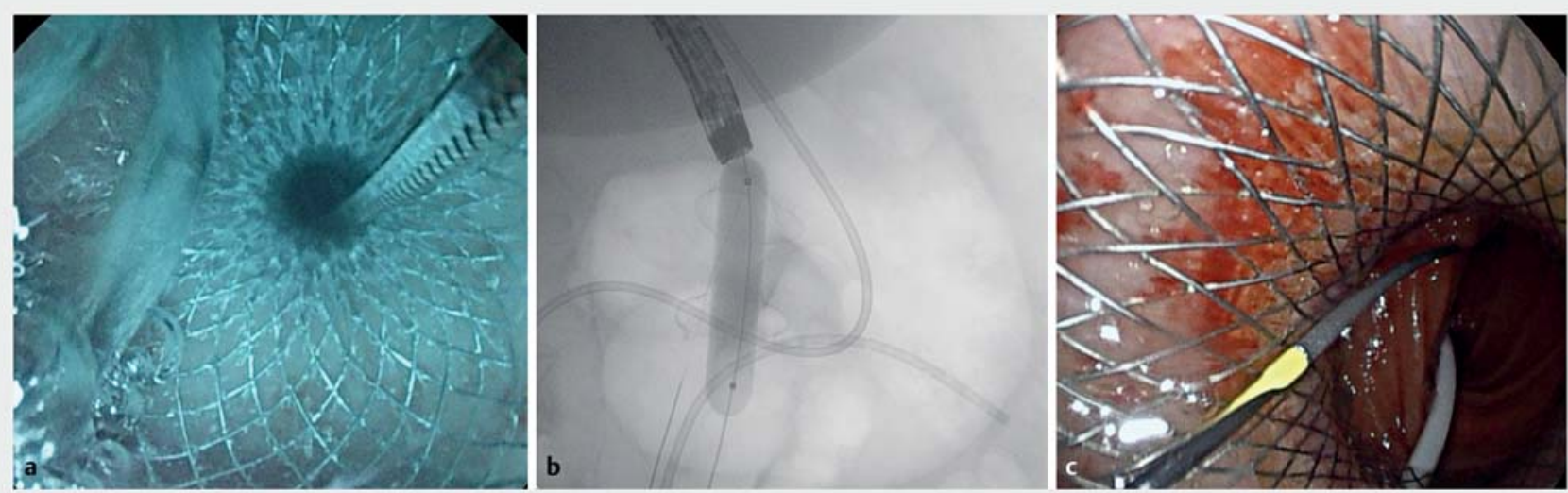

Fig. 3 The final stages of the procedure include: a spontaneous drainage of blue water, as seen endoscopically; b intra-LAMS dilation up to 12 or $15 \mathrm{~mm}$, seen on a fluoroscopic image; $\mathbf{c}$ trans-LAMS endoscopic visualization of the enteral loop and feeding tube.

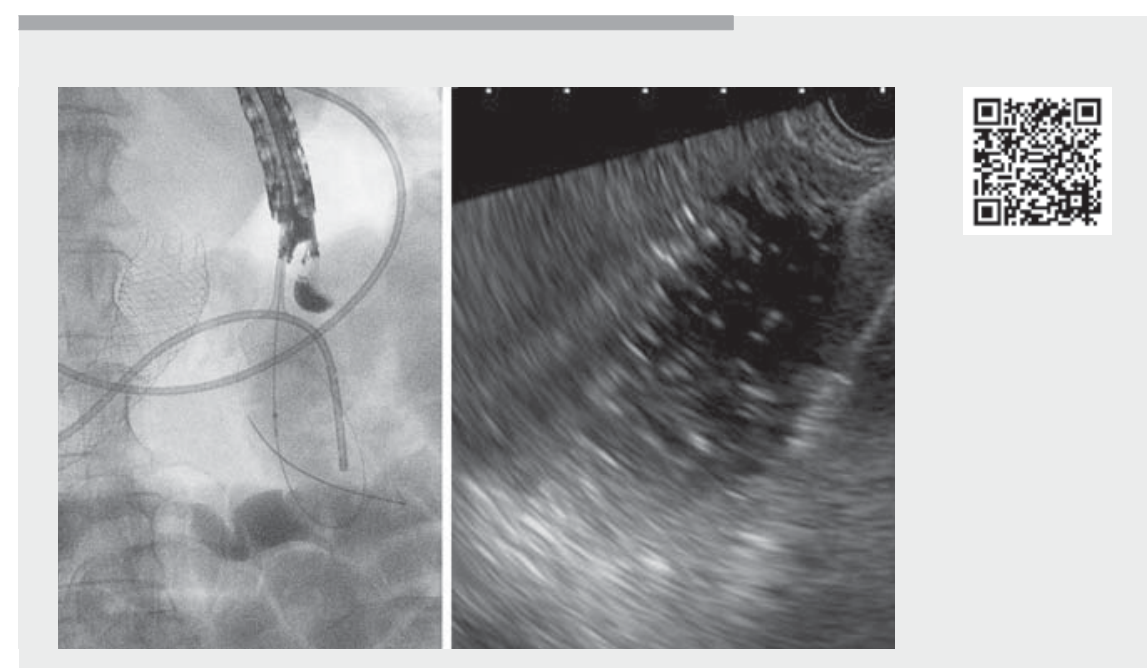

$\nabla$ Video 1 A teaching video demonstrating the technique of direct endoscopic ultrasound-guided gastroenterostomy using a feeding-tube waterjet system.

\section{Competing interests}

J. B. Gornals is a consultant for Boston Scientific. The remaining authors declare that they have no conflict of interest.

The authors

\section{Claudia F. Consiglieri ${ }^{1}$, Daniel Luna-}

Rodriguez ${ }^{1}$, Albert Garcia-Sumalla' ${ }^{\circledR}$, Sandra Maisterra', Julio G. Velasquez-Rodriguez ${ }^{1}$, Joan B. Gornals ${ }^{1,2} \odot$

1 Endoscopy Unit, Department of Digestive Diseases, Hospital Universitari de Bellvitge,

\section{Bibliography}

Endoscopy 2022; 54: E447-E448

DOI 10.1055/a-1625-3848

ISSN 0013-726X

published online 17.9.2021

(c) 2021. Thieme. All rights reserved.

Georg Thieme Verlag KG, Rüdigerstraße 14,

70469 Stuttgart, Germany

\section{ENDOSCOPY E-VIDEOS \\ https://eref.thieme.de/e-videos}

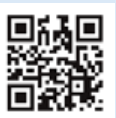

Endoscopy E-Videos is an open access online section, reporting on interesting cases and new techniques in gastroenterological endoscopy. All papers include a high quality video and all contributions are freely accessible online. Processing charges apply (currently EUR 375), discounts and wavers acc. to HINARI are available. (IDIBELL), University of Barcelona, Spain

2 Faculty of Health Sciences, Universitat Oberta de Catalunya, Barcelona, Spain

\section{Corresponding author}

\section{Joan B. Gornals, MD, PhD}

Endoscopy Unit, Dept. of Digestive Diseases, Hospital Universitari de Bellvitge - IDIBELL (Bellvitge Biomedical Research Institute), Feixa Llarga s/n, L'Hospitalet de Llobregat, Barcelona 08907, Spain jgornals@bellvitgehospital.cat
This section has its own submission website at

https://mc.manuscriptcentral.com/e-videos 